\title{
Исследование методом комбинационного рассеяния света влияния гидратации и состава смеси DOPCIDPPCIChol на формирование микроскопических доменов
}

\author{
Д.В. Шамаева", К.А. Окотруб, Н.В. Суровцев \\ Институт автоматики и электрометрии СО РАН \\ *E-mail: d.shamaeva@g.nsu.ru
}

DOI: $10.31868 /$ RFL2020.234

Tрехкомпонентная смесь DOPC $\backslash \mathrm{DPPC} \backslash \mathrm{Chol}$ (DOPC - 1,2-диолеоил-snглицеро-3-фосфохолин, DPPC - 1,2-дипальмитоил-sn-глицеро-3-фосфохолин, Chol - холестерин), является популярной моделью при изучении фазового состава биологических мембран [1]. Интерес к гидратированным структурам DOPC $\backslash$ PPPClChol обусловлен тем, что в физиологических условиях мембраны находятся в водной среде. В данной работе спектроскопия комбинационного рассеяния света с изотопной меткой применяется для анализа фазового состава высушенных и гидратированных планарных структур DOPClDPPClChol. Образцы планарных структур получены осаждением однослойных везикул из водной суспензии. В качестве изотопной метки используется дейтерированная форма фосфолипида DPPC. Исследованы составы: DOPC \DPPC $\backslash$ Chol $=1 \backslash 1 \backslash 1$, $\mathrm{DOPC} \backslash \mathrm{DPPC} \backslash \mathrm{Chol}=4 \backslash 4 \backslash 2, \mathrm{DOPC} \backslash \mathrm{DPPC} \backslash \mathrm{Chol}=3 \backslash 5 \backslash 2, \mathrm{DOPC} \backslash \mathrm{DPPC} \backslash \mathrm{Chol}=5 \backslash 3 \backslash 2 . \mathrm{O}$

Для всех составов наблюдается сосуществование дейтерированной и протонированной фаз. В высушенных образцах домены одной фазы имеют размер от 1 мкм до 10 мкм по горизонтали и от 5 мкм до 10 мкм по вертикали. В гидратированных образцах вертикальный и горизонтальный размеры доменов не превышают нескольких мкм, за исключением образца DOPC $\ \mathrm{DPPC} \backslash \mathrm{Chol}=3 \backslash 5 \backslash 2$, в локальной области которого есть область преобладания дейтерированной фазы размером около $15 \times 15$ мкм $^{2}$. В гидратированных образцах молекулы фосфолипидов более упорядочены, чем в высушенных образцах.

\section{Литература}

[1] Donaldson Jr. et al. J. Phys. Chem. Lett. 9, 1528-1533. (2018)

Научный руководитель - канд. физ.-мат. наук К. А. Окотруб 